DR HELEN ZEALLEY Chief Administrative Medical Officer Lothian Health Board Edinburgh

\section{Health Care Systems}

Edited by Hans-Martin Sass and

Robert O Massey, 368 pages, Dordrecht, £44.50, hbk, Kluwer, 1988

The aim of this volume is to get beyond issues of cost containment to the 'basic moral and cultural roots' of health systems and to ask how systems might be reconstructed so as to fit values. This quest started at an international symposium in West Germany in 1985.

Papers by Englehardt and Sass set the scene promisingly. Sass wants to see the individual citizen play a larger role in caring for his or her health 'for moral and cultural reasons, not primarily for economic reasons'. He wants to see costs and benefits of health programmes re-defined to cover costs in terms of loss of autonomy and benefits in public risk management and he sets out a framework for making choices at the margin. The Sass preferred choice would seem to be that government should concentrate on basic insurance medicine (BIM).

Detailed contributions on national health systems follow. Unfortunately, little use is made of the Sass framework. The day-to-day management of health systems seems to show a diminished concern for equity and access. The French experience with the end of ideology seems fairly typical. As Lacronique sums it up: 'It would be hard to find a single article advocating health policy in terms other than those which reflect a spirit of "real-politik" where any tribute to cost containment is passively accepted'. In the Netherlands 'budget cuts are necessary because of lack of funds', and although the Netherlands is said to have broken through to the higher perception that 'more health care expenditure does not necessarily result in improved health', it is not clear what effect if any this has had on policy.

The freshest contribution is by Feshbach on health in the USSR where use of performance indicators in hospital mortality rates discourages hospitals from admitting patients with a poor prognosis. Maynard makes some constructive suggestions for more information on costs, qualities and quantities as a prerequisite of any serious ethical debate at all. Delkeskamp-Hayes takes issue with Anglo-Saxon welfare economics in its use of altruism as grounds for collectivism.

The last sections cover microdecisions and philosophic principles but without managing to relate them very effectively. Viekhues contributes a vigorous essay against compulsion in prevention.

The book is most useful in providing contributions written from the standpoint of European individualism. Such individualism seems to have roots in Kant rather than in Adam Smith and at the moment seems to lack any real purchase on the pragmatic decisions taken by policy-makers in health systems. Individualism without market economics seems doomed to be a private and rather sketchy vision.

NICK BOSANQUET Professor of Health Policy University of London Egham Hill, Egham Surrey, TW20 OEX

\section{New Reproductive Techniques: A Legal Perspective}

Douglas J Cusine, 276 pages,
Aldershot, £25, hbk, Gower, 1988

Douglas Cusine has for a long time been a contributor to the debate on the legal issues of donor insemination. In this book he lucidly lays out the complexity of the legal pitfalls surrounding assisted conception, drawing particularly on the greater experience of donor insemination.

Two things strike me on reading this book. First, how naively we enter into treatment with donor gametes and embryos, usually not recognising the complex situations that may arise. There is such a strong assumption that all parties are acting in good faith that we find it difficult to anticipate that problems could occur in years to come. Presumably too, as family relationships become more tangled, this area is going to become even more fraught. All of us working in this field should clearly be aware of the consequences of our involvement, not only to protect ourselves, but particularly to ensure that the children conceived as a result of our intervention are adequately cared for.

Secondly, I was made aware that such laws as exist today in the field of assisted conception depend in the main part on case law. This leads to such anomalies as two more or less identical cases being judged in diametrically opposed directions. I was also shocked by the subjectivity of some of the judges, where summings-up are quoted in the book. Moral disapproval is clearly registered in some of the extracts and it becomes clear that current moral stances strongly influence judgements when there is no statute designed specifically to cover a complex situation.

It is obviously time to clarify the legal issues that arise from gamete and embryo donation, surrogacy and embryo research. Mr Cusine provides a comprehensive review of the Warnock Committee's report which addressed these issues and also draws attention to some situations that it did not cover satisfactorily. It was expected that the White Paper on Human Fertilisation and Embryology prepared in 1987, and drawing heavily on the findings of the Warnock Committee, would have been discussed in Parliament by now, but at the time of writing, this appears to have been shelved.

Mr Cusine has written an excellent summary of the legal issues raised bô the new reproductive techniques. His book also contains a useful bibliography. I shall find it a helpful guide as I contemplate counselling couples for donor insemination and in vitro fertilisation.

RUTH CURSON Subfertility Clinic King's College Hospital, London

\section{Confronting Death}

Richard W. Momeyer, 182 pages, Bloomington, Indianapolis, USA, $\$ 25.00 \mathrm{hbk}$, Indiana University Press, 1988

Confronting Death is a book written by a philosopher about attitudes to death. It is divided into two parts. The first part is about general attitudes to death, and by implication, to life also, and discusses the concept of 'good dying'. The second part builds upon this to consider specific problems, including suicide and the management of patients not in a position to make their own wishes clear.

The title is itself controversial in that accepting death is more generally advocated than confronting it. The 